\title{
A relação universidade e classes populares
}

\author{
Ivanise Monfredini
}

\begin{abstract}
O artigo trata da relação universidade e classes populares explicitada em publicações científicas de autoria de pesquisadores responsáveis por projetos de pesquisa/extensão de ciência para inclusão social, apoiados pela Secretaria de Ciência e Tecnologia para Inclusão Social. Num período recente implementaram-se no Brasil políticas de ensino superior e de ciência e tecnologia, com o objetivo de inclusão de populações historicamente excluídas. Neste artigo, abordar-se-ão as consequências dessas políticas, a partir de projetos voltados para catadores de materiais recicláveis e agricultores familiares. Os resultados sugerem que o fomento à realização desses projetos é importante para que os pesquisadores consigam escapar da lógica que, dentro das universidades, desvaloriza a extensão e a atuação junto a essas populações.
\end{abstract}

\section{Palavras-chave:}

universidad; política de ciência e tecnologia; relação universidade e classes populares. 


\section{La relación entre las universidades y las clases populares.}

Resumen: El artículo trata de la relación universidad y clases populares explicitada en publicaciones científicas de autoría de investigadores responsables por proyectos de investigación/extensión de ciencia para inclusión social, apoyados por la Secretaría de Ciencia y Tecnología para la inclusión social. En un período reciente se implementaron en Brasil políticas de educación superior y de ciencia y tecnología, con el objetivo de inclusión de poblaciones históricamente excluidas. Este artículo trata de las consecuencias de esas políticas, a partir de proyectos dirigidos a recolectores de materiales reciclables y agricultores familiares. Los resultados sugieren que el fomento a la realización de estos proyectos es importante para que los investigadores logran escapar de la lógica que, dentro de las universidades, desvaloriza la extensión y la actuación junto a esas poblaciones.

Palabras clave: universidad; políticas de ciencia y tecnología; relación entre universidad y clases populares.

\section{The relations between universities and working classes}

Abstract: The article deals with the relation between university and popular classes, made explicit in scientific publications of authorship from researchers responsible for research/outreach projects of science for social inclusion, supported by the Secretariat of Science and Technology for Social Inclusion. In the recent period, higher education and science and technology policies were implemented in Brazil, with the aim of including historically excluded populations. This article deals with the consequences of these policies, based on projects aimed to collectors of recyclable materials and family farmers. The results suggest that the support for these projects is important so that researchers are able to escape the logic that, within universities, depreciates outreach and the working together with these populations.

Keywords: university; science and technology policy, relation between university and popular classes.

\section{Rapports entre l'université et les classes populaires}

Résumé: L'article porte sur les rapports entre l'université et les classes sociales, tel qu'ils sont explicités dans des publications scientifiques écrites par des chercheurs responsables de projets de recherche ou d'extension de la science visant l'inclusion sociale et soutenus par le Secrétariat des Sciences et de la Technologie pour l'Inclusion Sociale. Le Brésil a récemment implanté des politiques d'enseignement supérieur, de sciences et de technologie ayant pout but l'inclusion de populations historiquement exclues. Cet article aborde les conséquences de telles politiques à partir de l'analyse de projets concernant les ramasseurs de matériaux recyclables et les agriculteurs familiaux. Les résultats suggèrent que le soutien apporté à la réalisation de ces projets est important pour que les chercheurs puissent échapper à la logique qui, dans les universités, dévalorisent l'extension et les actions auprès de ces populations.

Mot clés: université; politiques de science et technologie, rapports entre l'université et les classes populaires 


\section{Introdução}

O Brasil é um país marcado por desigualdades sociais, no qual poucos têm sido os momentos históricos em que se pode identificar a existência de um pleno compromisso dos governos com a educação pública. Ao longo do tempo as políticas públicas para a educação foram marcadas por descontinuidades, omissões e frequentes mudanças ministeriais. A educação do povo interessou especialmente aos governos autoritários (Getúlio Vargas e militares). A partir de meados do século XX os avanços na ampliação do acesso à educação básica e superior foram conquistas resultantes da pressão popular, que demandava mais escolas básicas e de ensino superior.

Em 2015 nota-se um incremento de aproximadamente 5\% de alunos matriculados no ensino superior brasileiro que se identificaram como pretos ou pardos (27\%), em relação ao ano anterior (22\%) (INEP 2016 e 2015). No período que corresponde ao início do século XXI, ampliaram-se as vagas no ensino superior público e privado, assim como houve esforço para incluir nesse nível de ensino grupos historicamente excluídos. Essas informações indicam avanços, sem que, no entanto, problemas históricos tivessem sido enfrentados.

A crescente inclusão no ensino superior de negros, indígenas, além dos jovens pobres, com renda familiar de até três salários mínimos foi resultado da criação da Lei de Cotas (Lei no 12.711, de 29 de agosto de 2012), do Programa Universidade para Todos (PROUNI Lei n¹1.096, de 13 de janeiro de 2005) e do REUNI (Decreto 6096 de 24 de abril de 2007).

Nesse mesmo início de século XXI, em 2003, o governo federal criou a Secretaria de Ciência e Tecnologia para Inclusão Social (SECIS). Com a sua criação o então Ministério da Ciência Tecnologia e Inovação ${ }^{1}$ (MCTI) pretendeu imprimir uma mudança nas Políticas de Ciência e Tecnologia (PCT) brasileiras com o objetivo de promover o desenvolvimento social.

Tais proposições indicam a inclusão das populações historicamente excluídas no Brasil, assim como a criação e difusão de conhecimentos pela universidade voltados para as classes populares, o apoio para divulgar e transformar em tecnologias e "patentes" os conhecimentos, saberes e técnicas geradas na prática por trabalhadores rurais, pequenos proprietários e suas famílias, os sem-teto e moradores das favelas urbanas, propiciando desenvolvimento econômico e social a essas populações.

Nesse momento histórico, em que populações até então excluídas começam a chegar aos campi das universidades, e em que a ciência voltada para essas populações também é incentivada ${ }^{2}$, retomam-se temas aparentemente superados, entre eles o da relação entre universidade e camadas populares, que agora estavam dentro e não apenas fora dos seus muros. 
Este não é um tema novo, mas que retorna diante da condição real de inserção dessas populações na universidade e de incentivo à produção de ciência e tecnologia da perspectiva dos historicamente excluídos. Para as ciências sociais é um momento importante para pensar a relação entre universidade e sociedade, privilegiando os movimentos sociais. Nesse sentido, Arroyo (2003, p.28) pergunta: "o que temos a aprender dos movimentos sociais?", para então responder que pensar as teorias pedagógicas a partir dessa perspectiva exige considerar os "vínculos tensos entre trabalho e educação". A leitura do texto nos instiga a pensar nos tempos e espaços marcados pela necessidade de sobrevivência, em que a desarticulação das condições de vida impulsionam a ação por direitos, inclusive à escola. Os movimentos populares atuaram de forma pedagógica na formação de lideranças, contribuindo para educar as camadas populares. Para Arroyo (2003, p.31) o potencial inspirador dos movimentos sociais:

[...] nos puxam para radicalizar o pensar e fazer educativos na medida em que nos mostram sujeitos inseridos em processos de luta pelas condições elementaríssimas, por isso radicais, de viver como humanos. Nos propõem como tarefa captar as dramáticas questões que são vividas e postas nessas situações limite e revelá-las, explicitá-las. E ainda captar como os sujeitos se formam, entrando eles mesmos como totalidades nos movimentos.

O texto de Arroyo sugere uma percepção para aquele momento, como repleto de possibilidades, tanto para os movimentos sociais quanto para as universidades brasileiras. Mas a universidade vem cumprindo a função de formar a elite dirigente do país, junto com a formação de profissionais para o mercado de trabalho. Apesar da grande diversificação que caracteriza o ensino superior brasileiro, a relação com os movimentos sociais foi historicamente marcante durante meados do século XX, no processo de resistência ao golpe militar.

Sobre esse aspecto, Bringel (2010) mostra que na América Latina, durante as décadas de 1960 e 1970, identifica-se um compromisso maior dos acadêmicos com os movimentos sociais. Depois, a partir dos anos 1980 houve um distanciamento provocado pela crescente especialização dos conhecimentos científicos e pela profissionalização do trabalho acadêmico. Para Bringel (2010, p.193), o neoliberalismo dos anos 1990 acentuou ainda mais esse distanciamento relacionado aos processos de crescente burocratização, privatização e, em alguns casos, da "busca [por] deslegitimar o modelo de pesquisa militante". No entanto, afirma ainda, Bringel (2010, p.193), "a irrupção de um novo ciclo de mobilização social na última década, na região, parece haver avivado novas fórmulas de atualização dos vínculos entre o pesquisador/intelectual e o compromisso militante [...]." 
É nesse cenário que se introduzem as políticas inclusivas para o ensino superior e para a ciência e tecnologia no Brasil. Decorridos pouco mais de dez anos da implementação desse conjunto de políticas, podem ter ocorrido mudanças na relação entre as classes populares e a universidade? Como alerta Bringel (2010) essa relação envolve alguns problemas que surgem no esforço de descolonizar e repensar a produção de conhecimentos, especialmente das ciências sociais, o que significa incorporar os diálogos com vários atores sociais, em diferentes enfoques, pressupondo a produção conjunta de conhecimento.

A pergunta se coloca nesse momento crítico em que direitos sociais conquistados recentemente vêm sendo perdidos junto com o desmonte do Estado brasileiro, após o golpe que destituiu o governo de Dilma Rousseff.

No cenário atual de aprofundamento da agenda neoliberal, em que se acirram as demandas do capital transnacional também para o setor do ensino superior, pergunta-se: a quem interessa essa instituição, a universidade, especialmente no Brasil, onde a produção científica é incipiente, se comparada a outras universidades de países centrais? Talvez a universidade não seja mais disputada por diferentes setores da sociedade, senão pelo capital e apenas como engrenagem de ampliação de rentabilidade. É o que sugere o diagnóstico de disfuncionalidade da universidade brasileira feito por Dagnino (2015). Para o autor, essa instituição, no Brasil, não tem nenhuma importância, tanto no que se refere à produção de conhecimentos exigido pelo capital, como para a população que sofre as consequências do processo de ampliação do capital. Ao longo do tempo, a universidade brasileira perdeu o lugar de produtora de conhecimentos para a elite dirigente. Essa disfuncionalidade se acentuou junto com o abandono definitivo do projeto nacional, com a opção política neoliberal implementada desde a década de 1990. Ao mesmo tempo, a universidade brasileira manteve-se distante das classes populares, resultando na sua atual disfuncionalidade.

Nesse cenário, a relação com os movimentos sociais pode se constituir uma alternativa à ressignificação social da universidade brasileira? Embora essa questão não se esgote nos limites deste artigo, foi a motivadora do estudo em andamento ${ }^{3}$ e sobre o qual se apresentam neste texto as primeiras análises produzidas a partir de informações contidas em artigos científicos sobre as populações beneficiárias em projetos de pesquisa e extensão apoiados pela SECIS.

A noção de mobilização do conhecimento como tem sido discutida no Grupo de Trabalho do CLACSO (Conselho Latino-Americano de Ciências Sociais) "Ciência social politizada" contribui para a análise. Naidorf e Perrotta (2015, p.26) propõem essa noção para as ciências sociais, considerando aqueles conhecimentos que se encontram prontos para utilização dos atores a quem se dirige esse conhecimento. Compreendida apenas dessa perspectiva a noção de mobilização do conhecimento pode confundir-se com as exigências de mercado, que também definem agendas científicas 
e utilização do conhecimento determinados pela busca de ampliação de margens de lucro.

A partir do conceito de ciência politizada proposto em 1969 por Oscar Varsavsky, Naidorf e Perrotta (2015, p.26) indicam outro sentido para a noção de mobilização do conhecimento fundada na ideia de ciência social politizada, que:

Lejos de la concientización, la iluminación o el espíritu civilizatorio y normatizador, la ciencia social politizada debería propender al diálogo como punto de partida, a la equivalencia de lo Otro y a la construcción de puentes de entendimiento con lo social, sin dejar de asumir el conflicto y la disputa como motor de los cambios emancipatorios.

A atuação conjunta de pesquisadores e classes populares em universidades brasileiras, tema que será desenvolvido neste texto, pode constituir pontes, além de novas agendas e conhecimento compartilhado, como sugerido na noção de mobilização do conhecimento em ciências sociais, por Naidorf e Perrotta (2015).

Apesar da crise em curso, nas universidades mantém-se viva a utopia de muitos daqueles que fazem essa instituição: de que se preserve a sua característica essencial que é o pensar como base da sua (re)criação.

Esse é o desafio que está posto: pensar alternativas para a universidade. Este texto tem esse objetivo, embora delimitando essa reflexão a um aspecto específico que é a identificação de resultados da realização de pesquisas/extensão para a inclusão social.

Iniciaremos com a apresentação dos aspectos metodológicos que envolvem o estudo e em seguida serão apresentados os resultados parciais da pesquisa em andamento, seguidos das considerações finais, possíveis até o momento.

\section{Ciência para Inclusão Social em Editais da SECIS: aspectos metodológicos}

O delineamento da pesquisa deu-se no contexto de política pública de ciência e tecnologia e ensino superior indicado acima. Em síntese, apresentam-se os primeiros aportes sobre a ciência para a inclusão social, objetivo da SECIS, no nível da prática de políticas, aspecto relevante no cenário brasileiro, no qual os próprios acadêmicos são, também, os principais atores na elaboração de políticas de ciência e tecnologia.

Apresenta-se a primeira parte do levantamento de informações realizado sobre as publicações (artigos e trabalhos publicados em anais), geradas a partir do desenvolvimento dos projetos de pesquisa/extensão aprovados e financiados pela SECIS em resposta a editais para apoio aos Catadores de Materiais Recicláveis (18/2005), Agricultura Familiar em Transição Agroecológica (20/2005), apoio aos Núcleos de Estudos 
e Centros Vocacionais Tecnológicos em Agroecologia (46/2012) e apoio à Segurança e Soberania Alimentar (82/2013)4. Esses editais foram escolhidos por estarem de acordo com o escopo da pesquisa que é aprofundar o estudo sobre a ciência para inclusão social.

A metodologia de pesquisa bibliográfica constituiu na identificação das publicações nos Currículos Lattes dos pesquisadores responsáveis, seguida da busca na Internet dos artigos e trabalhos publicados em anais de eventos, finalizando com a seleção, seguida de análise de conteúdo conforme Bardin (1995) e Franco (2012).

Nessa primeira fase da pesquisa, após identificação de títulos nos currículos dos pesquisadores, selecionaram-se textos que se referiam a processos de pesquisa/extensão desenvolvidos junto a ou com as populações beneficiárias. Nesses casos, identificaram-se duas possibilidades:

1. levantamentos de informação primária sobre as populações beneficiárias com base em procedimentos não participativos em que os sujeitos fornecem as informações a serem analisadas pelos pesquisadores. Nesses casos, as informações contidas nos textos contribuíram para a formulação das unidades de contexto ${ }^{5}$ em relação a cada uma das diferentes populações beneficiárias

2. textos que se referem a procedimentos participativos que envolvem a população em uma, algumas ou todas as fases do processo de pesquisa/extensão.

As unidades de análise organizaram-se em torno dos procedimentos participativos indicados pelos pesquisadores nos textos e dos resultados também indicados por eles. Para essa unidade de análise, consideraram-se os processos de formação, aprendizagem, participação e dificuldades, relatados em relação à população beneficiária.

Finalmente, cabe ressaltar que do total de 75 publicações encontradas online cujos títulos sugerem referências às populações beneficiárias, 48 (64\%) de fato abordam esse aspecto. Destas, apenas 25 publicações fazem referência a abordagens participativas. O destaque nesse aspecto são os editais 20/2005 e 46/2012 em que na quase totalidade dos textos analisados houve referência a metodologias participativas.

Esse resultado sugere a complexidade da relação entre universidade e classes populares, principalmente no que se refere ao edital de apoio aos catadores de materiais recicláveis. Para esse edital (18/2005) observou-se que poucos artigos faziam referência aos catadores. De modo geral, os artigos divulgavam os resultados relacionados ao desenvolvimento de processos de produção e de materiais, e ainda divulgavam em linguagem popular esses processos, visando informar à população sobre limpeza, ecologia e resíduos sólidos. Muito poucos faziam referência aos catadores e sua participação na pesquisa/extensão. Como se identificou nas publicações, os catadores, 
mesmo organizados em associações e cooperativas, enfrentam sérios desafios relacionados às precárias condições de vida e trabalho, o que pode justificar as poucas referências ao desenvolvimento de ações conjuntas, pela dificuldade em realizá-las.

No entanto, as publicações referentes aos editais 20/2005 e 46/2012 da área de agroecologia revelaram o potencial formativo contido no fomento da SECIS. Os projetos resultaram em várias publicações que tratam das ações desenvolvidas junto aos/ com os agricultores.

A seguir apresentaremos as análises qualitativas dos textos.

\section{Os Catadores de Materiais Recicláveis}

O Edital CT-Agro/CT-Hidro/MCT/CNPq nº 018/2005 explicitava a urgência no atendimento às famílias que viviam da catação nos lixões ${ }^{6}$ e chamava para apresentação, projetos de extensão.

Por meio da busca online obtiveram-se 18 títulos entre artigos e trabalhos apresentados em anais de eventos. Após a leitura restaram nove, que efetivamente tratavam de processos e atividades envolvendo os catadores de materiais recicláveis. A análise a seguir considera essas publicações ${ }^{7}$.

A leitura desses textos evidenciou que os pesquisadores/extensionistas trabalharam com perspectivas participativas no diagnóstico dos problemas enfrentados pelos catadores organizados em cooperativas. Para exemplificar, um dos textos detalha a técnica da grupalidade na sua concepção ideológica, que também ressaltou "as vantagens do desenvolvimento das atividades de forma cooperativa em pequenos grupos". (Daltro Filho; et.al. 2009).

As ações realizadas após esses diagnósticos foram diversas e determinadas tanto pelas necessidades dos catadores quanto dos pesquisadores. Num dos casos realizaram-se os cursos solicitados pelos catadores sobre os temas: "Reciclagem de Materiais Poliméricos; Socialização e Integração; Capacitação Gerencial voltada à Administração de Negócios e Saúde Ocupacional e Segurança do Trabalho" (Borsoi et. al.2011, p.2). Em outro caso, a equipe atuou apoiando a organização e constituição da cooperativa de catadores, por meio da conscientização da população da cidade quanto à necessidade de separação do lixo reciclado, para valorizar e facilitar o trabaIho dos catadores.

Ainda em outro caso, as ações orientaram-se pela autogestão sustentada pelos pilares da formação política e para o trabalho, em que as decisões são tomadas coletivamente, assim como os saberes são exercitados e compartilhados pelo coletivo de catadores. Nesse caso, a organização conquistada pelos catadores e o trabalho conjunto resultaram na criação da Associação dos Catadores, do entreposto da mesma associação e da realização de parcerias para trocas de experiências com outras 
associações. Nesse mesmo caso, a autora do texto chama a atenção para os processos de mudanças nos conhecimentos de pesquisadores e catadores envolvidos ao final dos dois anos. Várias Tecnologias Sociais foram criadas nesse processo além do próprio entreposto, as Planilhas para Controle da Produção.

Notou-se também o desenvolvimento de atividades participativas com o objetivo de colaborar com a organização das cooperativas, especialmente no que se refere a potencializar o ganho econômico dos cooperados. Num dos casos realizou-se um estudo de produção e arrecadação financeira da cooperativa para potencializar a comercialização e ampliar a arrecadação. Esta ampliação era necessária pois pretendia-se que a cooperativa passasse a recolher o INSS dos cooperados, tendo em vista um dos problemas apontados: a ausência de qualquer proteção social como um dos aspectos da desvalorização social dos catadores (Borsoi et. al 2011).

Num dos textos em que os autores Braz, Filho e Zanin (2009) se propõem a discutir a gestão participativa em cooperativas na cidade de São Carlos, os autores observam a disposição dos cooperados em relação ao empreendimento e em trazer para as cooperativas princípios autogestionários. Mas notam também a dificuldade de alguns cooperados envolverem-se com o dia a dia do empreendimento.

Em todos os textos observa-se a semelhança de problemas apontados pelos cooperados: percepção de desvalorização social relacionada ao preconceito e à ausência de proteção social e garantias trabalhistas, desunião entre os cooperados, sentimento de não pertencimento em função, também, dos limitados ganhos que os empurram à realização de vários bicos concomitantes. Diante disso, em pelo menos três dos textos observa-se uma perspectiva de contribuir com a sustentabilidade econômica dessas cooperativas como aspecto central para que outros processos mais amplos de formação pudessem ser desenvolvidos (o pertencimento, a responsabilidade, a cidadania). Nesses casos, as perspectivas discutidas com os catadores foram: incluir por meio da economia solidária-cooperativa; inclusão no mundo do trabalho por meio da cadeia produtiva da reciclagem; comércio justo e solidário, com a contribuição do design.

Mas, como é apontado em todos as experiências, mesmo organizados o trabalho dos catadores não é suficiente para sua subsistência, dificultando a sua fixação nas cooperativas.

\section{Os Agricultores Familiares e a Agroecologia}

No caso da agroecologia, agruparam-se informações encontradas em dois editais: o MCT/CNPq/MDA/CT-Agro - n 020/2005 de "Seleção Pública de Propostas para Apoio a Projetos de Geração e Disponibilização de Tecnologias de Base Ecológica Apropriadas à Agricultura Familiar" e a Chamada MCTI/MEC/MAPA/CNPq No 46/2012, cujo objetivo foi selecionar projetos de Agroecologia e Produção Orgânica 
que envolvessem implantação e/ou manutenção de Núcleo de Estudo em Agroecologia e Produção Orgânica (NEA) ou a implantação de Centro Vocacional Tecnológico (CVT).

Para estes dois editais foram encontrados 33 artigos e trabalhos apresentados em anais de eventos online. Após a leitura restaram 20 que efetivamente tratam de processos e atividades envolvendo os agricultores e/ou suas associações. A análise a seguir considera estas publicações ${ }^{8}$.

O grande número de textos nos impede de realizar uma abordagem texto a texto. Nos casos em que os pesquisadores/extensionistas relataram a participação dos agricultores, utilizaram-se várias metodologias para orientar o trabalho. Para o diagnóstico, encontram-se referências ao Diagnóstico Rural Participativo (DRP), questionários discutidos coletivamente e Estudo de Caso Participativo.

As metodologias pedagógicas citadas nos textos foram: Educação Ambiental, Pesquisa-ação-participativa, Etnobotânica, Ecologia de Saberes, Experimentação Participativa, Diálogo participativo, Gestão Conjunta entre os Diferentes Sujeitos do Processo, Horto Medicinal Comunitário, Oficinas Participativas, Aulas Expositivas, Jogo Pedagógico, Peça Teatral e Permacultura.

Em relação aos instrumentos e métodos utilizados para desenvolvimento das ações extensionistas encontramos referências à Agroecologia, Permacultura, Experimentação Participativa, Metodologia Participativa e Dialógica para Construção Conjunta de Soluções, Etnociência e Oficina de Construção.

As mesmas metodologias podem ser indicadas como pedagógicas e como instrumentos para o desenvolvimento das ações devido ao fundamento que as orientam: da troca de saberes, da valorização dos saberes tradicionais a partir do reconhecimento dos conhecimentos dos agricultores e a sua inclusão na tomada de decisão e desenho das ações e tecnologias a serem adotadas.

Os objetivos dessas ações, explicitados nos textos, podem ser sintetizados em três grandes ideias: promover processos de educação ambiental, incluindo nele a valorização dos conhecimentos dos agricultores; revelar/identificar situação das experiências de transição agroecológica na região e impulsionar a transição agroecológica, incluindo a perspectiva da sustentabilidade econômica das cooperativas, assentamentos e das unidades agroecológicas familiares.

Destaquem-se ainda as soluções delineadas em conjunto, como Tecnologias Sociais, para enfrentamento de alguns dos problemas detectados: Compostagem, Horto Medicinal Comunitário, Sanitário Compostável, Viveiro de Mudas, Controle de Pragas e Apiário.

Em alguns desses textos identificou-se uma outra significação para os agricultores e a atividade agrícola, na ideia de "camponeses que realizam agricultura camponesa", que expressa a resistência coletiva ao avanço da agricultura capitalista que expropria 
a terra, as tradições da agricultura camponesa, as sementes, os conhecimentos, deixando um rastro de degradação ambiental e humana.

As contradições explicitadas nesses casos exemplificam os problemas e limites apontados por alguns dos autores, enfrentados pelos agricultores familiares em transição agroecológica, seja nos assentamentos, seja em unidades familiares localizadas em áreas de proteção ambiental: avanço do capitalismo sobre as áreas rurais, degradação do solo, das água e do meio ambiente, dificuldade de acesso a linhas de crédito oficiais; migração para zonas urbanas; utilização das moradias rurais apenas como dormitórios, para, durante o dia, ir buscar renda fora; dificuldade no escoamento da produção, questões de gênero que podem induzir problemas de saúde da mulher e das crianças; processo de aculturação e perda de tradições transmitidas oralmente de uma geração a outra; individualismo; ausência de organização comunitária dificultando o enfrentamento aos problemas.

Por outro lado, os relatos contidos nos textos sinalizam a importância da organização coletiva dos agricultores familiares, assim como as tecnologias sociais como instrumentos potencializadores de organização. Os relatos sugerem que a experiência comum contribui para união entre os agricultores e suas famílias e, o mais essencial, para a relação de todos com a terra e o ambiente natural, fortalecendo alternativas e perspectivas comuns no enfrentamento desses graves problemas. O enfrentamento conjunto não resulta, sempre, mudança rápida e significativa nos níveis de renda, já que esses resultados dependem de fatores como a capacidade de produção da região e do escoamento do produto, dentre outros.

\section{Considerações Finais sobre a Relação entre Universidade e Camadas Populares em Projetos de Ciência para Inclusão Social}

Pesquisadores/extensionistas da área da agroecologia têm invertido a hierarquia do modelo científico hegemônico, em que a extensão é o polo mais desvalorizado, realizando pesquisa a partir da extensão. Nesse processo não só as pautas de pesquisa são orientadas de fora para dentro da universidade, alimentando linhas de pesquisa, mas também conhecimentos novos são inseridos de fora para dentro.

Nesses casos, em que há criação conjunta de conhecimento, o processo de produção de inovação tecnocientífica leva em conta os conhecimentos populares, tradicionalmente classificados como não científicos.

Os relatos contidos nos textos, também em relação aos catadores, evidenciaram o potencial formativo nas diversas ações desenvolvidas em conjunto pelos beneficiários e pelos pesquisadores/extensionistas em que o poder de decisão, como sugerem os textos, foi compartilhado. 
Nelas podem ser geradas experiências comuns, democráticas, em que pese a cultura autoritária também existente nas universidades. Mas como todo processo que se realiza no âmbito da história lenta (Martins, 2011), que caracteriza o processo político-social brasileiro, é possível afirmar que o fomento à realização de ciência e tecnologia voltado para as populações historicamente excluídas é importante para que o pesquisador consiga escapar da lógica que desvaloriza a extensão e a atuação junto a essas populações, como cita Bringel (2010).

As ações implementadas por pesquisadores e populações beneficiárias, são permeadas por contradições. Embora em apenas um dos textos se tenham notado reflexões sobre essas contradições, elas são importantes para análise da relação universidade-classes populares. Bortoli (2009) é a pesquisadora que realiza essa análise lúcida da experiência vivida junto aos catadores, indicando o quanto pesquisadores e população beneficiária organizada precisam aprender e insistir no sentido de ampliar social e politicamente essas experiências, para não serem capturados (pesquisadores e populações beneficiárias) pelas aparentes inclusões sugeridas pelo agronegócio, no caso dos agricultores, o que resulta no abandono da agricultura, e pelos programas sociais que mal garantem a subsistência, no caso dos catadores.

O exercício coletivo de reflexão e criação de tecnologias sociais para enfrentamento dos problemas precisa ser constantemente renovado e realizado, sob o risco de que pesquisadores, catadores e agricultores sejam capturados pelas hierarquias sociais.

Conclui-se que estas são as possibilidades e os riscos postos na política de ciência para inclusão social da SECIS, pois como prática historicamente determinada, realiza-se contraditoriamente. Estipular políticas de fomento a ações, como foram esses casos financiados pela SECIS, pode, de fato, contribuir para estreitar as relações entre universidade e classes populares, e indiretamente para que a universidade resgate sua significação social num momento em que suas práticas são cada vez mais determinadas pela busca da rentabilidade. No entanto, as ações precisam incluir a perspectiva de transformação social, ou seja, da formação política.

As informações contidas nos artigos também sugerem que a universidade pode se constituir num espaço qualificado, visando à formação em conjunto com as classes populares. No entanto, essas possibilidades são tensionadas pelo acirramento da crise do capital. Os textos permitem identificar essas tensões e fragilidades resultantes desse processo, tanto no caso dos catadores como dos agricultores.

\section{Notas}

1 Corresponde atualmente ao Ministério da Ciência, Tecnologia, Inovação e Comunicação (MCTleC).

2 Acrescente-se ainda a institucionalização do fomento à extensão universitária, também em 2003 , com a criação do Programa Pró-Extensão (PROEXT).

3 Realizado com financiamento da Fapesp (15/04326-3). 
${ }^{4}$ Nessa publicação excluímos a apresentação da análise qualitativa dos quatro textos referentes ao edital 82/2013, devido à necessidade de economia espaço. No entanto a exclusão não prejudica a análise contida nas considerações finais.

5 Bardin (1995) e Franco (2012).

${ }^{6}$ O texto que se segue foi publicado, numa primeira versão em Pesquisaeduca (2016).

7 Por falta de espaço não serão citadas todas essas 9 publicações. Em Fontes Primárias encontram-se aquelas citadas neste artigo.

8 Por falta de espaço não serão citadas todas essas 20 publicações. Em Fontes Primárias encontram-se aquelas citadas neste artigo.

\section{Referências:}

Instituto Nacional de Estudos e Pesquisas Educacionais Anísio Teixeira (INEP). (2016). Sinopse da Educação Superior 2015. [Disponível em: http://portal.inep.gov.br/basica-censo-escolar-sinopsesinopse, consultado em 13/01/2017].

Instituto Nacional de Estudos e Pesquisas Educacionais Anísio Teixeira (INEP). (2015). Sinopse da Educação Superior 2014. [Disponível em: http://portal.inep.gov.br/web/guest/sinopses-estatisticasda-educacao-superior consultado em 13/03/2017].

Brasil, Secretaria Nacional de Ciência e Tecnologia para Inclusão Social (SECIS) (2003). [Disponível em http://www.mct.gov.br/index.php/content/view/78953.html, consultado em 01/02/2014].

Arroyo, M. (2003). Pedagogias em movimento. O que temos a aprender dos movimentos sociais? Currículo sem Fronteiras, 3(1), 28-49. [Disponível em www.curriculosemfronteiras.org consultado em 21/02/2017].

Bardin, L. (1995). Análise de conteúdo. Lisboa: Edições 70.

Bringel, B. (2010). Ativismo transnacional. O estudo dos movimentos sociais e as novas geografias pós-coloniais. Estudos de Sociologia, Revista do Programa de Pós-Graduação em Sociologia da UFPE, 16(2), 185-215. Disponível em: [http://www.revista.ufpe.br/revsocio/index.php/revista/article/ view/122 consultado em 27/02/2017].

Dagnino, R. (2015). La universidad latinoamericana del futuro que la sociedad esta construyendo. Cuestiones de Sociología, 12. [Disponível em: http://www.cuestionessociologia.fahce.unlp.edu.ar/ consultado em 01/11/2016].

Franco, M. L. P. B. (2012). Análise de conteúdo. 4. ed. Brasília: Liber Livros.

Martins, J. S. (2011). A política do Brasil: lúmpen e místico. São Paulo: Contexto.

Naidorf, J. \& Perrotta, D. (2015). La ciencia social politizada y móvel de una nueva agenda latinoamericana orientada a prioridades. Revista de la Educación Superior, 44(174), 19-46.

Fontes Primárias:

Andrade, F. M. C., Casali, V. W. D., Cupertino, M. C. (2010). Seleção de indicadores, monitoramento e sistematização de experiências com homeopatia em unidades agrícolas familiares. Revista Brasileira de Agroecologia, 5 (1), 61-73. 
Ballesteros, K. et al. (2009). Lixo e compostagem como ferramentas para conscientização ambiental em uma comunidade da Reserva de Desenvolvimento Sustentável do Tupé - Manaus/AM . Revista Brasileira de Agroecologia, 4, 1755-1759.

Bezerra, M. M., \& Scudeller, V. V. (2011). O lúdico na valorização do saber local sobre plantas medicinais numa escola da zona rural de Manaus-Amazonas. Cadernos de Agroecologia, 6, 14-20.

Braz, L. L., Filho, A. G. A. \& Zanin, M. (2009). A gestão participativa da rede de cooperativas de catadores de São Carlos na unidade de beneficiamento de plástico. In: Zanin, M. \& Gutierrez, R. F. (orgs.) Economia solidária: tecnologias em reciclagem de resíduos para geração de trabalho e renda. (pp. 128-134). São Carlos: Claraluz.

Borsoi, C., et al. (2011). Informações sobre as dificuldades enfrentadas nas centrais de triagem obtidas de catadores durante a realização de cursos de capacitação: estudo de caso em Caxias do Sul. $26^{\circ}$ Congresso Brasileiro de Engenharia Sanitária e Ambiental. ABES - Associação Brasileira de Engenharia Sanitária e Ambiental.

Bortoli, M.A. (2009). Catadores de materiais recicláveis: a construção de novos sujeitos politicos. Revista Katályses Florianópolis, 1 (XII), 105-114.

Daltro F. J. et.al. (2016) A importância socioambiental de uma cooperativa de catadores de resíduos sólidos: o caso da CARE de Aracaju-SE. [Disponível em: http://www.saneamentobasico.com. br/portal/wp-content/uploads/2013/02/A-importancia-socioambiental-de-uma-cooperativa-decatadores-de-resíduos-sólidos consultado em 06/09/2016].

Scudeller, V. V. et al (2009). Horto medicinal comunitário como instrumento de promoção da saúde, trabalho coletivo e práticas agroecológicas na Comunidade Julião, RDS Tupé, Manaus-AM. Revista Brasileira de Agroecologia, 4, 1695-1698.

Silva, E. H., Coelho, F. M. G., \& Alves Filho, E. (2006). Inovação e sustentabilidade econômica em projetos de assentamento da reforma agrária. Revista Econômica do Nordeste, 37(2), 216-233.

Silva, N. S., et al (2013). Sistematização de experiências visando à sustentabilidade e conversão agroecológica de agricultores familiares no Território da Borborema, Estado da Paraíba. Revista Verde de Agroecologia e Desenvolvimento Sustentável, 8, 1-11.

Siqueira, H. M. de, et al. (2010). Transição agroecológica e sustentabilidade dos agricultores familiares do Território do Caparaó ES. Revista Brasileira de Agroecologia, 5, 247-263.

Sousa, R. P. et al. (2013). Fortalecendo territórios de vida: agricultores familiares e educadores unidos na construção da Agroecologia na Amazônia paraense. Revista Agriculturas, 10, 12-19. 
Ivanise Monfredini

Doutora em Educação: História, Política, Sociedade pela Pontifícia Universidade Católica de São Paulo. Integra o Programa de Pós-graduação em Educação da Universidade Católica de Santos, Brasil. Financiamento da

Fundação de Amparo à Pesquisa do Estado de São Paulo - FAPESP.

Email: ivanise.monfredini@unisantos.br

ORCID : 0000-0001-8492-9826

Correspondência

Ivanise Monfredini

Av. Conselheiro Nébias, 300

Campus Dom Idílio José Soares

Universidade Católica de Santos

11015- Santos, São Paulo (Brasil)

Data de submissão: Dezembro 2016

Data de avaliação: Janeiro 2017

Data de publicação: Março de 2018 